\title{
Prognostic Significance of BCL2 Protein in Diffuse Large Cell Lymphoma of Head and Neck; Relation to Response to Chemotherapy
}

\author{
Heba A. Elhendawy ${ }^{1}\left(0\right.$, Afaf T. Ibrahiem $^{2,3}$, Hoda S. Elmahdi², Amany M. Omar ${ }^{4}$ \\ ${ }^{1}$ Department of Oral and Maxillofacial Pathology, Faculty of Dentistry, Mansoura University, Mansoura City, Egypt \\ ${ }^{2}$ Department of Pathology, Faculty of Medicine, Mansoura University, Mansoura City, Egypt \\ ${ }^{3}$ Department of Pathology, Faculty of Medicine, Northern Border University, Arar, Saudi Arabia \\ ${ }^{4}$ Department of Pathology, Faculty of Medicine, Al-Minia University, Al-Minia, Egypt \\ Email: helhendawy15@yahoo.com, afafziad1976@gmail.com, Dr.hodaelmahdi1978@gmail.com, Sabry_amany@yahoo.com
}

How to cite this paper: Elhendawy, H.A., Ibrahiem, A.T., Elmahdi, H.S. and Omar, A.M. (2020) Prognostic Significance of BCL2 Protein in Diffuse Large Cell Lymphoma of Head and Neck; Relation to Response to Chemotherapy. Open Journal of Pathology, 10, 76-92.

https://doi.org/10.4236/ojpathology.2020.1 $\underline{02008}$

Received: February 27, 2020

Accepted: April 6, 2020

Published: April 9, 2020

Copyright $\odot 2020$ by author(s) and Scientific Research Publishing Inc. This work is licensed under the Creative Commons Attribution International License (CC BY 4.0).

http://creativecommons.org/licenses/by/4.0/

\begin{abstract}
Diffuse large B cell lymphoma (DLBCL) is a heterogeneous disease that displays a highly variable clinical outcome. It is a neoplasm of large transformed $B$ cells with a diffuse growth pattern. DLBCL is the most common type of non-Hodgkin's lymphoma (NHL) (31\% of all cases). Approximately half of patients with DLBCL are cured with current chemotherapy regimens. The purpose of this study was to evaluate $\mathrm{BCl} 2$ expression in 45 patients diagnosed with DLBCL of head and neck region and correlate the level of its immunohistochemical expression with different clinicopathological variables with emphasis upon patients' age, gender, nodal or extra-nodal location of lymphoma, patients' response to chemotherapy, progression-free survival (PFS) and overall survival (OS). A retrospective analysis of 45 patients diagnosed to have DLBCL. A cut off value of $\geq 50 \%$ protein expression denoted BCL2 positivity. Out of 45 cases, 36 cases (80\%) revealed BCL2 positive expression and 9 cases $(20 \%)$ were BCL2 negative. We found statistically significant differences in BCL2 expression regarding different patients' responses to chemotherapy, patients' OS and PFS ( $\mathrm{p} \leq 0.05)$. No statistically significant differences in BCL2 expression regarding the patients' Ann Arbor clinical stage, age group and tumor site (nodal or extra-nodal, $\mathrm{p}>0.05$ ) using the Chi-square test. BCL2 expression was analyzed in relation to 5 years OS and PFS using Kaplan Meier curves and Log Rank test for survival analysis. Cases that demonstrated BCL2 positivity revealed shortened OS and PFS with highly statistically significant differences among the studied variables $(p=0.000)$. We also found that patients who respond well to the chemotherapeutic regimen had negative BCL2 expression, the differences were statistically signifi-
\end{abstract}


cant $(\mathrm{p}=0.015)$. In conclusion, BCL2 expression could be considered a predictor for patients' chemotherapeutic response, OS and PFS.

\section{Keywords}

Diffuse Large B-Cell Lymphoma, BCL2, Chemotherapy, OS, PFS

\section{Introduction}

The head and neck region is one of the most common sites for the extra-nodal lymphomas. Most of the primary oral and para oral NHLs is DLBCL histological type [1] [2]. DLBCL is a heterogeneous disease that shows various outcomes [3]. It is a neoplasm of large transformed B cells with a diffuse growth pattern. Generally, DLBCL is a common histological type of NHL (31\% of all cases) [4]. Almost 50\% of DLBCL cases are cured with CHOP standard regimen (CTX, Adriamycin, VCR, prednisolone) [5] [6]. However, the remaining 50\% are chemoresistant and this regimen is not able to cure them [7]. The latter group usually recurs after CHOP-induced remission with a short disease-free interval [8]. Other strategies in treatment as a combination between chemotherapeutics and mononuclear antibodies, or intensive chemotherapeutics associated with transplantation of bone marrow may be effective to them [9]. Thus, it would be extremely beneficial if we could detect previously which patients need more intensive treatments. Nowadays, researchers have been trying to find prognostic factors that help in predicting who will experience good or unsatisfactory response.

Apoptosis is one of the mechanisms which affect chemotherapy response and has been thoroughly investigated. Evidence has been accumulated in recent years showing that many and perhaps all chemotherapeutic agents affect tumor cell killing by inducing apoptosis [8]. Intrinsically chemoresistant tumors are unable to activate the apoptotic machinery and may therefore resistant to induction of cell death by chemotherapeutic agents. The BCL2 protein is considered to be an important multidrug resistance agent. BCL2 is a member of a related and interacting family of proteins, some of which (e.g., Bcl-xl) are antiapoptotic [10]. The prognostic impact of BCL2 overexpression is seen in various studies. Some studies have shown no difference, whereas others have shown reduced survival [11]. In the post rituximab era, the prognostic significance of BCL2 expression has been found to be controversial, the prognostic significance of BCL2 shown in some studies, while others not showing any prognostic significance [12]. The association between BCL2 expression and disease-free survival has been assessed in several studies [8] [13]. In aggressive NHL, these studies have led to the belief that BCL2 family proteins have an important role in chemosensitivity or chemoresistance of DLBCL. The purpose of our study was to evaluate BCL2 expression in DLBCL of the head and neck region and correlates its expression with different clinicopathological variables with emphasis upon patients' chemothe- 
rapeutic response, PFS and OS.

\section{Materials and Methods}

\subsection{Patients Selection}

This retrospective study was conducted from January 2014 to January 2019 (5 years interval). Patients who were included to our study diagnosed with primary DLBCL that were aroused from the head and neck region. All cases included to our study had complete medical records and with confirmed diagnosis of DLBCL by sample immunophenotyping. After exclusion of cases had insufficient biopsy speciemen and those with missing medical records, Forty-five paraffin blocks for DLBCL cases with thorough medical and clinicopathological data were retrieved from archives of the Pathology laboratory and Oncology unit of Oncology Center, Faculty of Medicine, Mansoura University. Patients' follow up data were obtained from the medical reports belong to the internal medicine department. All patients who were included in our study were treated with RCHOP-like therapies (rituximab, cyclophosphamide, prednisone, doxorubicin hydrochloride and vincristine). After completion of treatment, patients were followed every 3 months intervals. The follow up comprised clinical examination and periodic ultrasonography for the head and neck region. In addition, chest $\mathrm{X}$-ray, bone scan, and abdominal ultrasonography were performed when relapse was suspected. Overall survival (OS) and disease-free survival (DFS) data were retrieved from patients' medical reports. Five years OS was calculated from the dates of diagnosis to death or to the dates of the last follow up. PFS was calculated from the dates of first progression, death, relapse or the last follow up. Previous clinicopathological and follow-up data were obtained after getting approval from the institutional review board. This study was approved by the local ethical committee.

\subsection{Immunohistochemical Staining}

All selected blocks were cut at $4 \mu \mathrm{m}$ thickness. The slices were placed on coated slides. After xylene deparaffinization, the sections were rehydrated in descending grades of alcohol followed by water. Antigen retrieval was performed by using $0.01 \mathrm{M}$ citric acid buffer $(\mathrm{pH}=6.0)$ and heated for 10 minutes in the microwave. The sections were then incubated in a blocking medium $\left(3 \% \mathrm{H}_{2} \mathrm{O}_{2}\right)$ for five minutes followed by washing with distilled water. Rabbit monoclonal anti-human antibody (clone; EPR 5111, 1:50, dilution, Abcam, 1 Kendall Square, Suite B2304, Cambridge, MA 02139-1517, USA (was used against BCL2 antibody. Assessment of BCL2 positivity was performed by staining sections of hyperplastic human tonsillar tissue that used as a positive control at the same time and under the same conditions. Negative control slides obtained by replacement of the primary antibodies by plain phosphate buffer saline. Immuno-detection was executed using Power-stain TM1.0 poly HRP DAB kit for mouse + rabbit (Cat No 52-0017, Genemed Biotechnologies, Inc., 458 Carlton Ct., South San Francisco, CA 94080, USA). Immune staining was performed based on the manufacturer's 
instructions. Immunoreaction was visualized by adding DAB Counterstaining of slides that were performed with the Mayer hematoxylin.

\subsection{Immunostaining Evaluation}

Immunohistochemical results were evaluated semiquantitatively. The BCL2 positivity was determined by cytoplasmic staining (brown) of neoplastic cells. The internal control was $\mathrm{T}$ cells. The percentage of positive cells in the whole section after the exclusion of the areas of reactive $\mathrm{T}$ cells was determined. It was scored negative if $5 \%$ or less of neoplastic cells were stained. In this study, the value of BCL2 was considered weak positive if 6 to less than $50 \%$ were brown stained. For statistical analysis, we considered negative and weak positive (low expression) and high expression if $\geq 50 \%$ of tumor cells were brown stained [14]. The histopathological and immunohistochemical evaluation was done by two pathologists independently and blindly. The images were acquired utilizing a Nikon Eclipse microscope equipped with a 5-megapixel cooled CCD camera and the Image-Pro + AMS7 software.

\subsection{Statistical Analysis}

Statistical analysis of the data was done by using the Excel program and the Statistical Package for Social Science (SPSS) version 22 program. The description of the data was done in the form of mean (+/-) Standard Deviation (SD) for quantitative data, while in the form of frequency and proportion for qualitative data. The analysis of the data was done by one way ANOVA, to test statistical significant difference between groups and Wilcoxon multiple comparisons test for comparison of each two groups. Pearson correlation co-efficiency test was used to test the association between the different variables. A chi-square test was used to compare between two groups for qualitative data. The construction of survival curves was conducted using the Kaplan-Meier method, and the significance was assessed with the log-rank test. Univariate and multivariate survival analyses were performed with the Cox proportional hazards model to detect an independent prognostic factor. Using the univariate and multivariate analysis, the outliers were detected and cleaned from the data set. A P-value less than or equal to 0.05 was considered statistically significant.

\section{Results}

\subsection{Clinicopathological Characteristics of Studied Cases}

A total of 45 patients of DLBCL were identified and included in the study. Regarding gender, our study included 24 males (53.3\%) and 21 females (46.7\%) with male to female ratio 1.14:1. The research included 35 cases $(77.8 \%)$ were younger than 60 years old, while the rest were older than 60 years old (10 cases, $22.2 \%)$. DLBCLs that aroused from lymph nodes of head and neck region comprised 28 cases (62.2\%), while the rest aroused from extranodal location (Table 1). The majority of the studied cases presented as localized disease in stage I and 
Table 1. Clinico-pathological features of studied cases.

\begin{tabular}{cccc}
\hline \multicolumn{2}{c}{ Clinic-pathological variables } & Frequency & Percent \\
\hline \multirow{2}{*}{ Gender } & male & 24 & $53.3 \%$ \\
& female & 21 & $46.7 \%$ \\
Age group & $<60$ years & 35 & $77.8 \%$ \\
Tumor location & $\geq 60$ years & 10 & $22.2 \%$ \\
& Nodal & 28 & $62.2 \%$ \\
Ann Arbor clinical stage & Extranodal & 17 & $37.8 \%$ \\
Tumor recurrence & Stage I \& II & 33 & $73.3 \%$ \\
Deaths & Stage III \& IV & 12 & $26.7 \%$ \\
& yes & 18 & $40 \%$ \\
Patient response to & yes & 27 & $60 \%$ \\
chemotherapy & Response by $<3$ courses & 14 & $20 \%$ \\
& Response by $\geq 3$ courses & 16 & $31.1 \%$ \\
& chemoresistant & 15 & $35.6 \%$ \\
\hline
\end{tabular}

II according to Ann Arbor clinical staging system (33 cases, 73.3\%). DLBCLs of advancing clinical stages (III and IV) demonstrated in 12 cases (26.7\%).

All participant of the study received chemotherapy. Patients' response to chemotherapeutic treatment was assessed during the follow up visits in accordance with international working group recommendations for response criterion for NHL. Patients were divided into 3 groups according to their response to the administered chemotherapy as follow: respond to less than 3 chemotherapeutic courses (14 cases, $31.1 \%$ ), respond to three or more chemotherapeutic courses (16 cases, 35.6\%) and chemoresistant group (15 cases, 33.3\%). Recurrence of the tumor during follow up demonstrated in 18 cases (40\%). Nine of the followed cases $(20 \%)$ were died during follow up. Patients' clinicopathological data is shown in Table 1.

\subsection{BCL2 Expression in Relation to Different Clinicopathological Variables}

We selected a cutoff of $\geq 50 \%$ protein expression for BCL2 positivity. In the total cases BCL2 positive rate was $80 \%$ (36 out of 45 cases; Figures $1(D)-(F)$ ). The relationship between different clinicopathological variables and BCL2 expression was assessed using Chi-square test. BCL2 expression had no statistically significant associations with tumor location either nodal or extranodal $(\mathrm{p}=0.758)$, Ann Arbor clinical stage $(P=0.736)$ and patient's age $(\mathrm{p}=0.37)$. Table 2 illustrates the data.

BCL2 expression was positively expressed in 17 out of the 18 cases (94.4\%) that had recurrence during follow up. Nineteen out of 27 non-recurring cases (70.4\%) had positive BCL2 expression. Chi-square test revealed a statistically 


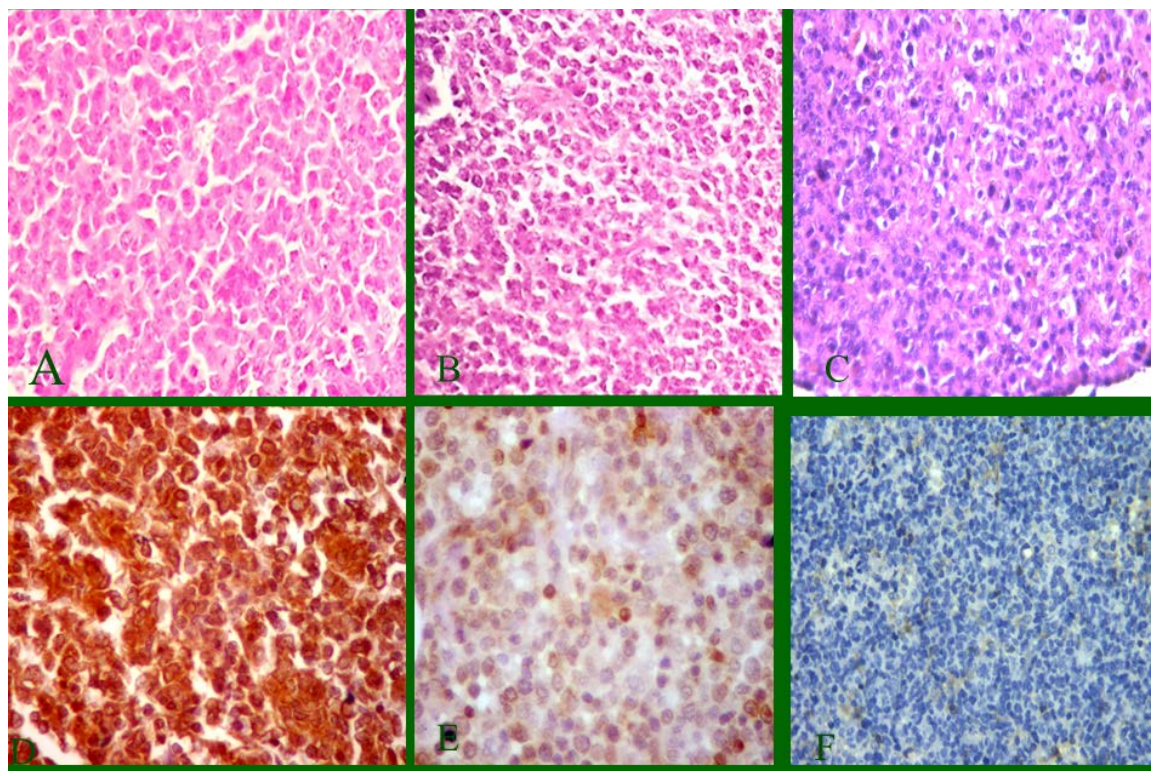

Figure 1. Hematoxylin and eosin staining showed DLBCL with large cells with abundant eosinophilic cytoplasm, vesicular nuclei and single or multiple nucleoli (photo A, B and C $\times 400)$. BCL2 immunostaining showed diffuse strong staining ( $>50 \%$ of neoplastic cells, photo $\mathrm{D} \times 400)$, focal expression $(6 \%:<50 \%$ of neoplastic cells show positive low BCL2 expression, photo $\mathrm{E} \times 400$ ), and negative $\mathrm{BCl} 2$ staining (5\% or less) of neoplastic large cells with positive staining of reactive $\mathrm{T}$ cells (positive internal control (photo $\mathrm{F} \times 400$ ).

Table 2. BCL2 expression in relation to different clinicopathological variables.

\begin{tabular}{|c|c|c|c|c|c|}
\hline variables & Groups & $\begin{array}{c}\text { Positive } \\
\text { BCL2 }\end{array}$ & $\begin{array}{c}\text { Negative } \\
\text { BCL2 }\end{array}$ & total & $\begin{array}{l}\text { Chi-square } \\
\text { test P-value }\end{array}$ \\
\hline \multirow{3}{*}{ Tumor site } & Nodal & $22(78.6 \%)$ & $6(21.4 \%)$ & 28 & \multirow{3}{*}{0.758} \\
\hline & & & & & \\
\hline & Extranodal & $14(82.4 \%)$ & $3(17.6 \%)$ & 17 & \\
\hline \multirow{2}{*}{$\begin{array}{l}\text { Ann } \\
\text { Arbor stage }\end{array}$} & I \& II & $26(78.8 \%)$ & $7(21.2 \%)$ & 33 & \multirow{2}{*}{0.736} \\
\hline & III \& IV & $10(83.3 \%)$ & $2(16.7 \%)$ & 12 & \\
\hline \multirow{3}{*}{ Age group } & $<60$ years & $27(77.1 \%)$ & $8(22.9 \%)$ & 35 & \multirow{3}{*}{0.37} \\
\hline & & & & & \\
\hline & $\geq 60$ years & $9(90 \%)$ & $1(10 \%)$ & 10 & \\
\hline \multirow{2}{*}{ recurrence } & Present & $17(94.4 \%)$ & $1(5.6 \%)$ & 18 & \multirow{2}{*}{0.048} \\
\hline & Free & $19(70.4 \%)$ & $8(29.6 \%)$ & 27 & \\
\hline \multirow{2}{*}{$\begin{array}{c}\text { Died/alive } \\
\text { status }\end{array}$} & Died & $9(100 \%)$ & Zero & 9 & \multirow{2}{*}{0.094} \\
\hline & Alive & $27(75 \%)$ & $9(25 \%)$ & 36 & \\
\hline Patient & - Respond to $<3$ courses & $8(57.1 \%)$ & $6(42.9 \%)$ & 14 & \multirow{3}{*}{0.033} \\
\hline \multirow{2}{*}{$\begin{array}{l}\text { Response to } \\
\text { chemotherapy }\end{array}$} & - Respond to $\geq 3$ courses & $14(87.5 \%)$ & $2(12.5 \%)$ & 16 & \\
\hline & - Resistant & $14(93.3 \%)$ & $1(6.7 \%)$ & 15 & \\
\hline
\end{tabular}

Chi-square test; $\mathrm{p}$-value significant if $\leq 0.05$.

significant difference in BCL2 expression according to incidence of recurrence $(\mathrm{P}=0.048)$.

All cases that died during follow up demonstrated positive BCL2 expression (9 
cases, 100\%). On the other hand, BCL2 was positively expressed in 27 (75\%) out of 36 alive cases. Although Chi-square test revealed no statistically significant difference in BCL2 expression between the two groups (died and alive), but the $\mathrm{P}$-value $(\mathrm{p}=0.09)$ approximates the value required to reach significance.

BCL2 expression was varied among the three different patients' responses to chemotherapy. Fourteen out of 15 chemoresistant cases (93.3\%) had positive BCL2 expression. Fourteen out of 16 Patients (87.5\%) who received and responded to $\geq 3$ chemotherapeutic courses had positive BCL2 expression. Eight out of 14 patients $(57.1 \%)$ who responded to less than three chemotherapeutic courses had positive BCL2 expression. Chi-square test revealed a statistically significant difference in BCL2 expression among the mentioned three groups of patients according to their response to the taken drugs $(P=0.033$; Figure 2). BCL2 expression in the studied DLBCLs could predict the patients' chemotherapeutic response (ANOVA test $\mathrm{P}$-value $=0.015)$.

\subsection{BCL2 Expression and Patients' Overall Survival}

Patients' OS were analyzed in relation to status of BCL2 expression using Kaplan Meier method and log rank test was used for comparing the variables. The mean OS in patients with positive BCL2 expression was 37.5 months, while those who had negative BCL2 expression was 56 months. In other words, the mean OS was greater in BCL2 negative patients $(\mathrm{n}=9)$ as compared to the positive ones $(\mathrm{n}=$ 36, 56 Vs 37.5 months; $p=0.000$ ) Table 3, Figure 3. BCL2 expression in tumor could predict the 5 years OS $\left(\mathrm{R}^{2}=40.5 \%, \mathrm{p}=0.000\right.$, Table 4$)$.

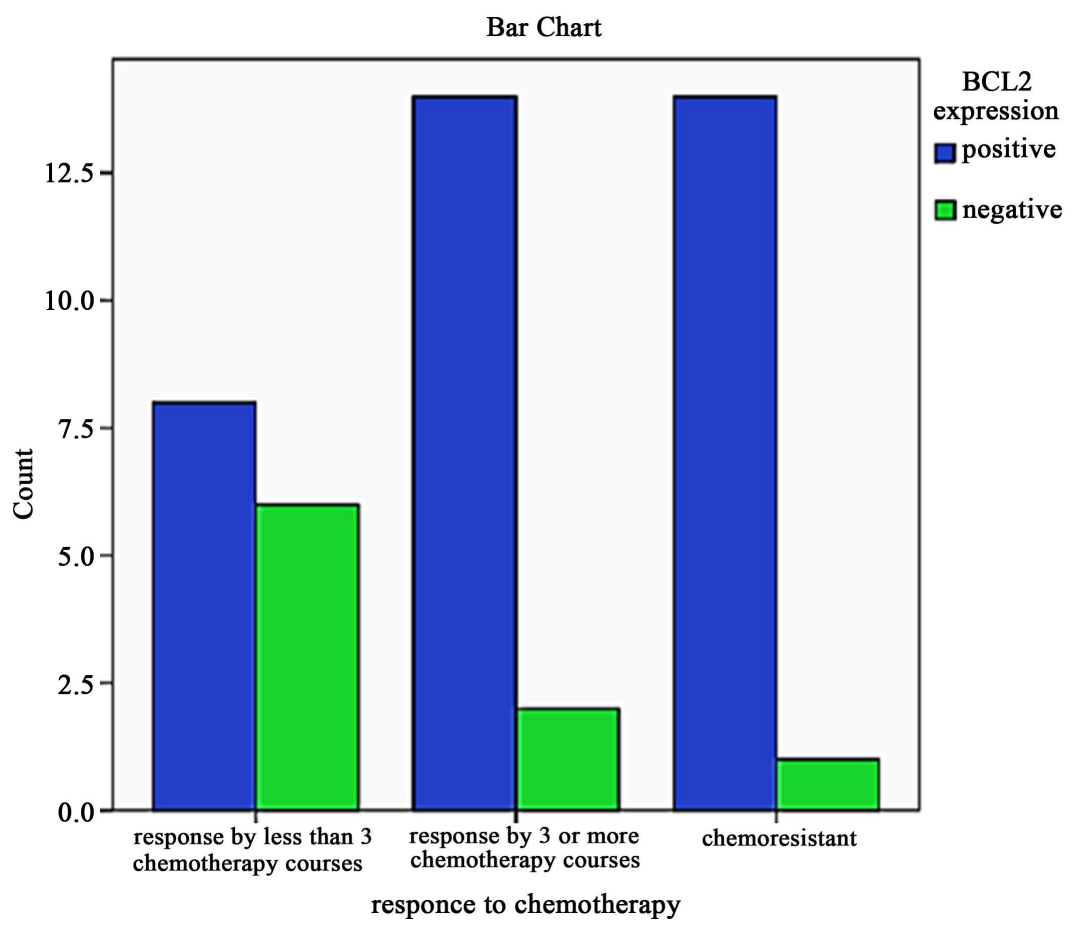

Figure 2. BCL2 expression in relation to different patients' responses to chemotherapeutic treatment. 

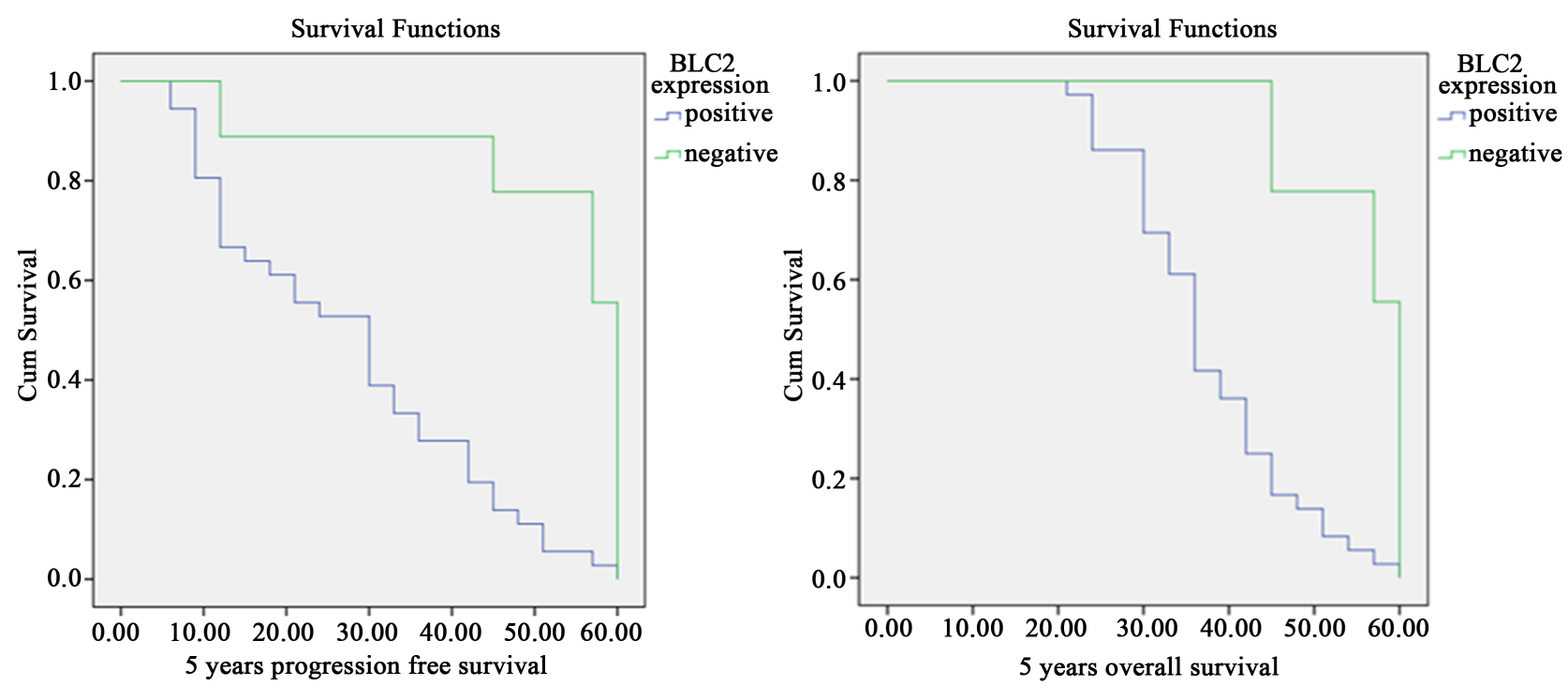

Figure 3. BCL2 expression in relation to 5 years overall survival and 5 years progression free survival.

Table 3. Patients' overall survival in relation to BCL2 expression.

\begin{tabular}{|c|c|c|c|c|c|c|c|c|c|}
\hline \multirow{5}{*}{$\begin{array}{c}\text { BCL2 } \\
\text { expression }\end{array}$} & \multicolumn{4}{|c|}{ Mean $^{a}$} & \multicolumn{4}{|c|}{ Median } & $\begin{array}{l}\text { Log Rank } \\
\text { test (Sig.) }\end{array}$ \\
\hline & \multirow{4}{*}{ Estimate } & \multirow{2}{*}{\multicolumn{3}{|c|}{$\begin{array}{l}\text { 95\% Confidence } \\
\text { Interval }\end{array}$}} & \multirow{4}{*}{ Estimate } & \multirow{4}{*}{$\begin{array}{l}\text { Std. } \\
\text { Error }\end{array}$} & \multicolumn{2}{|c|}{ 95\% Confidence } & \\
\hline & & & & & & & Int & val & \\
\hline & & \multirow{2}{*}{$\begin{array}{l}\text { Std. } \\
\text { Error }\end{array}$} & Lower & Upper & & & Lower & Upper & \\
\hline & & & Bound & Bound & & & Bound & Bound & \\
\hline positive & 37.500 & 1.619 & 34.327 & 40.673 & 36.000 & 1.268 & 33.515 & 38.485 & 0.000 \\
\hline negative & 56.000 & 2.121 & 51.842 & 60.158 & 60.000 & 0.000 & & & \\
\hline Overall & 41.200 & 1.754 & 37.762 & 44.638 & 39.000 & 2.321 & 34.450 & 43.550 & \\
\hline
\end{tabular}

Table 4. Prediction of OS by BCL2 expression.

\begin{tabular}{|c|c|c|c|c|c|c|c|c|c|}
\hline \multirow[b]{2}{*}{ Model } & \multirow[b]{2}{*}{$\mathrm{R}$} & \multirow[b]{2}{*}{ R Square } & \multirow[b]{2}{*}{$\begin{array}{l}\text { Adjusted } \\
\text { R Square }\end{array}$} & \multirow{2}{*}{$\begin{array}{l}\text { Std. Error } \\
\text { of the } \\
\text { Estimate }\end{array}$} & \multicolumn{5}{|c|}{ Change Statistics } \\
\hline & & & & & $\begin{array}{l}\text { R Square } \\
\text { Change }\end{array}$ & $\begin{array}{c}\mathrm{F} \\
\text { Change }\end{array}$ & df1 & df2 & $\begin{array}{l}\text { Sig. F } \\
\text { Change }\end{array}$ \\
\hline 1 & $0.636^{\mathrm{a}}$ & 0.405 & 0.391 & 9.18416 & 0.405 & 29.214 & 1 & 43 & 0.000 \\
\hline
\end{tabular}

a. Predictors: (Constant), BCL2 expression; Dependent Variable: 5 years overall survival.

Patients' OS was analyzed in relation to patient age, gender, tumor location nodal or extranodal, tumor clinical stage and different patient's responses to the taken chemotherapeutic drugs. None of these variables had effect on patient's OS except for patient's age and response to chemotherapy. In more words, mean survival was greater in patients under age of 60 years as compared to those above 60 years old $(\mathrm{n}=42,8$ Vs 35.7 months; $\mathrm{p}=0.044)$. Also, chemoresistant cases had shorter OS as compared to cases that respond to 3 or more chemotherapeutic courses and cases that respond to less than three courses (32.2 Vs $42.18 \mathrm{Vs}$ 49.71 months respectively; $\mathrm{p}=0.000$ ). 


\subsection{BCL2 Expression and Progression Free Survival}

Patient PFS was analyzed in relation to BCL2 expression using Kaplan Meier survival curves. The mean PFS in patients with positive BCL2 expression was 27.4 months as compared to those who had negative BCL2 expression 52.3 months, a high statistically significant difference in PFS according to the status of BCL2 expression (p-value $=0.000$; Table 5, Figure 3).

Patients' PFS was analyzed in relation to patient age, gender, tumor location either nodal or extranodal, clinical stage and different patient responses to chemotherapy. All these independent variables had significant difference in relation to PFS except for gender and tumor location. In more words, patients who diagnosed with tumor in advanced clinical stage (III and IV), the age $\geq 60$ years old, chemoresistant cases had shortened PFS when compared to patients who had tumors in localized clinical stage (I and II), patient age younger than 60 years, patients who respond to chemotherapy $(\mathrm{P}<0.05$, log Rank test; Figures 4-7). BCL2 expression in tumor could predict patients PFS $\left(\mathrm{R}^{2}=28.7 \%\right.$, $\mathrm{p}$-value $=0.000$, Table 6 ).

Finally, we analyzed patients' OS in addition to PFS in relation to BCL2 expression, Ann Arbor clinical stage, incidence of recurrence and different patients' responses to chemotherapy as covariables using COX regression model. BCL2 expression and different patients' chemotherapeutic response were the only two independent variables that affect patients' OS and PFS ( $\mathrm{p}<0.05$, Table 7 and Table 8).

Table 5. BCL2 expression in relation to PFS.

\begin{tabular}{|c|c|c|c|c|c|c|c|c|c|}
\hline \multirow{5}{*}{$\begin{array}{c}\text { BCL2 } \\
\text { expression }\end{array}$} & \multicolumn{4}{|c|}{ Mean $^{\mathrm{a}}$} & \multicolumn{4}{|c|}{ Median } & \multirow{2}{*}{$\begin{array}{c}\text { Log Rank } \\
\text { test } \\
\text { P-value } \\
\text { (sig.) }\end{array}$} \\
\hline & \multirow{4}{*}{ Estimate } & \multirow{2}{*}{\multicolumn{3}{|c|}{$\begin{array}{l}\text { 95\% Confidence } \\
\text { Interval }\end{array}$}} & \multirow{4}{*}{ Estimate } & \multirow{4}{*}{$\begin{array}{l}\text { Std. } \\
\text { Error }\end{array}$} & \multicolumn{2}{|c|}{ 95\% Confidence } & \\
\hline & & & & & & & Inte & val & \\
\hline & & Error & Lower & Upper & & & Lower & Upper & \\
\hline & & & Bound & Bound & & & Bound & Bound & \\
\hline positive & 27.417 & 2.689 & 22.146 & 32.687 & 30.000 & 4.387 & 21.401 & 38.599 & \\
\hline negative & 52.333 & 5.294 & 41.957 & 62.710 & 60.000 & 0.000 & & & 0.000 \\
\hline Overall & 32.400 & 2.807 & 26.899 & 37.901 & 30.000 & 4.311 & 21.550 & 38.450 & \\
\hline
\end{tabular}

Table 6. Progression free survival in relation to BCL2 expression.

\begin{tabular}{|c|c|c|c|c|c|c|c|c|c|}
\hline \multirow[b]{2}{*}{ Model } & \multirow[b]{2}{*}{$\mathrm{R}$} & \multirow{2}{*}{$\begin{array}{c}\mathrm{R} \\
\text { Square }\end{array}$} & \multirow{2}{*}{$\begin{array}{l}\text { Adjusted } \\
\text { R Square }\end{array}$} & \multirow{2}{*}{$\begin{array}{l}\text { Std. Error } \\
\text { of the } \\
\text { Estimate }\end{array}$} & \multicolumn{5}{|c|}{ Change Statistics } \\
\hline & & & & & $\begin{array}{l}\text { R Square } \\
\text { Change }\end{array}$ & $\begin{array}{c}\mathrm{F} \\
\text { Change }\end{array}$ & df1 & $\mathrm{df} 2$ & $\begin{array}{c}\text { Sig. F } \\
\text { Change }\end{array}$ \\
\hline \multirow[t]{3}{*}{1} & $0.535^{\mathrm{a}}$ & 0.287 & 0.270 & 16.08752 & 0.287 & 17.272 & 1 & 43 & 0.000 \\
\hline & Model & & Sum of Squares & $\mathrm{df}$ & Mean & quare & $\mathrm{F}$ & & Sig. \\
\hline & Regre & sion & 4470.050 & 1 & 447 & 050 & 17.27 & & $0.000^{\mathrm{b}}$ \\
\hline \multirow[t]{2}{*}{1} & Resic & & $11,128.750$ & 43 & 258 & 808 & & & \\
\hline & To & & $15,598.800$ & 44 & & & & & \\
\hline
\end{tabular}

ANOVA a. Dependent Variable: 5 years progression free survival; b. Predictors: (Constant), BCL2 expression. 


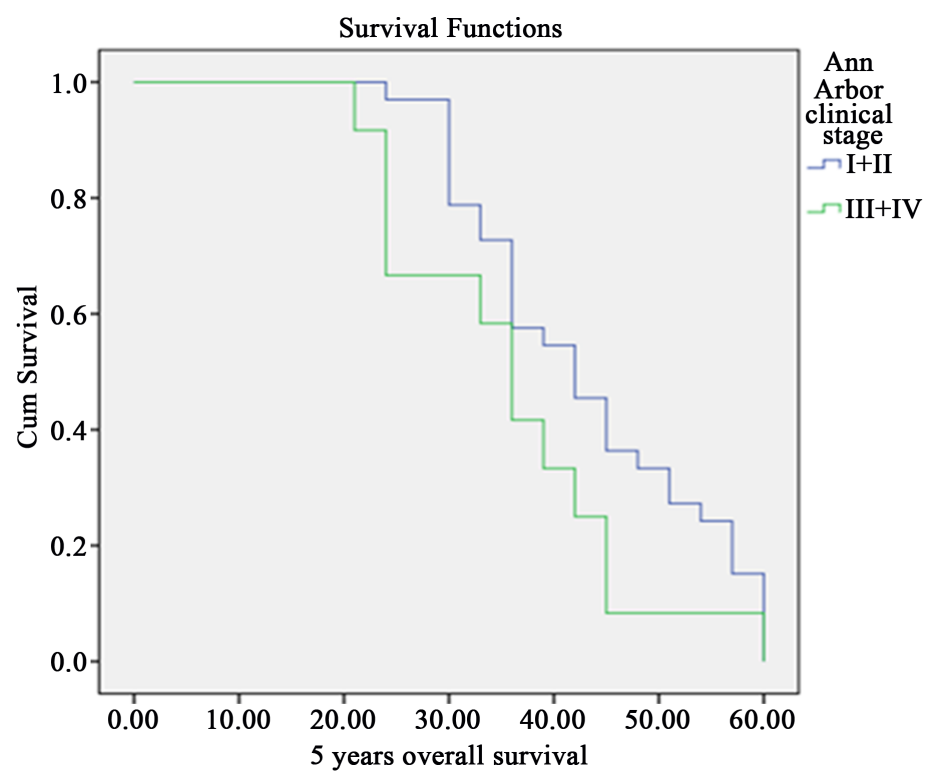

Figure 4. Progression free survival in relation to Ann Arbor clinical stage.

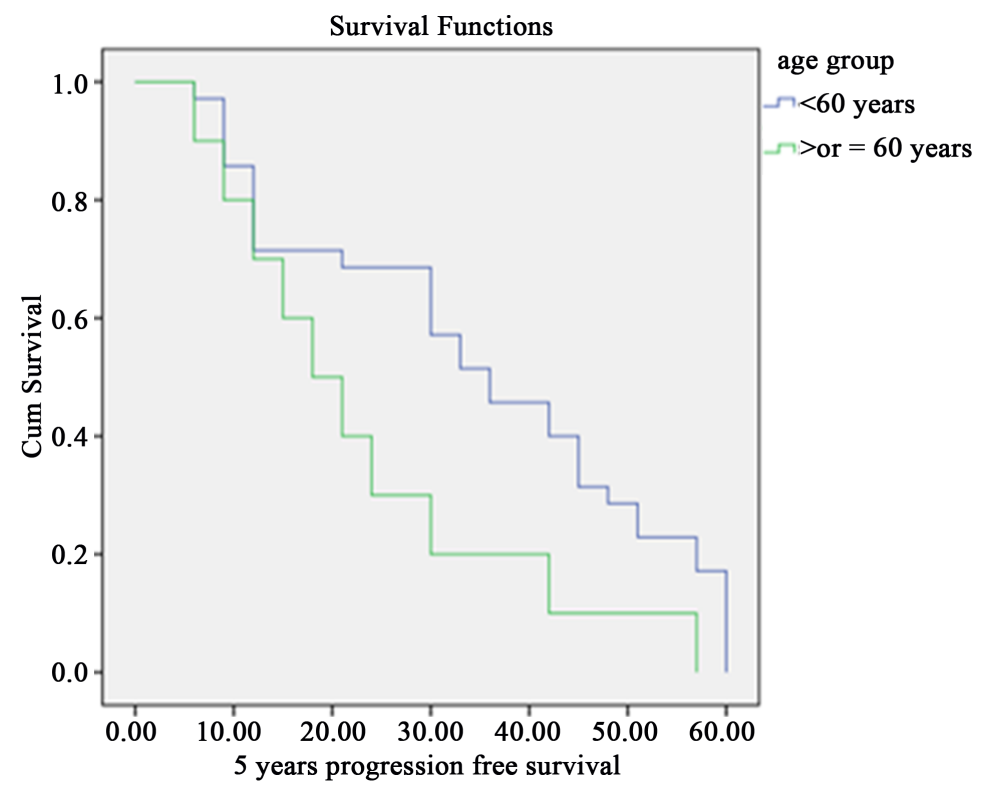

Figure 5. Progression free survival in relation to patient age.

Table 7. Analysis of OS in relation to covariables (COX regression model).

\begin{tabular}{ccccccc}
\hline \multicolumn{7}{c}{ Variables in the Equation } \\
\hline B & SE & Wald & df & Sig. & Exp (B) \\
\hline stage & 1.007 & 0.642 & 2.457 & 1 & 0.117 & 2.736 \\
BCL2 & 1.215 & 0.450 & 7.303 & 1 & 0.007 & 3.369 \\
recurrence & 0.344 & 0.498 & 0.477 & 1 & 0.490 & 1.411 \\
chemotherapy & & & 7.659 & 2 & 0.022 & \\
Chemotherapy (1) & 1.816 & 0.736 & 6.096 & 1 & 0.014 & 0.163 \\
Chemotherapy (2) & 1.763 & 0.643 & 7.512 & 1 & 0.006 & 0.172 \\
\hline
\end{tabular}




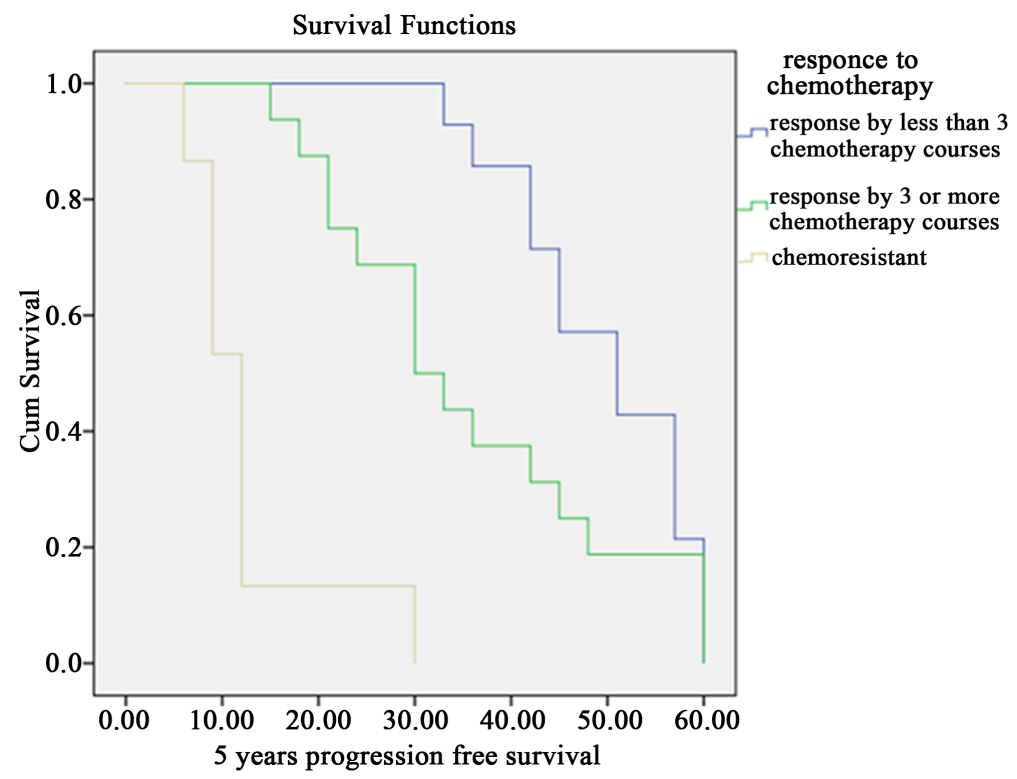

Figure 6. Progression free survival in relation to patients' chemotherapeutic response.

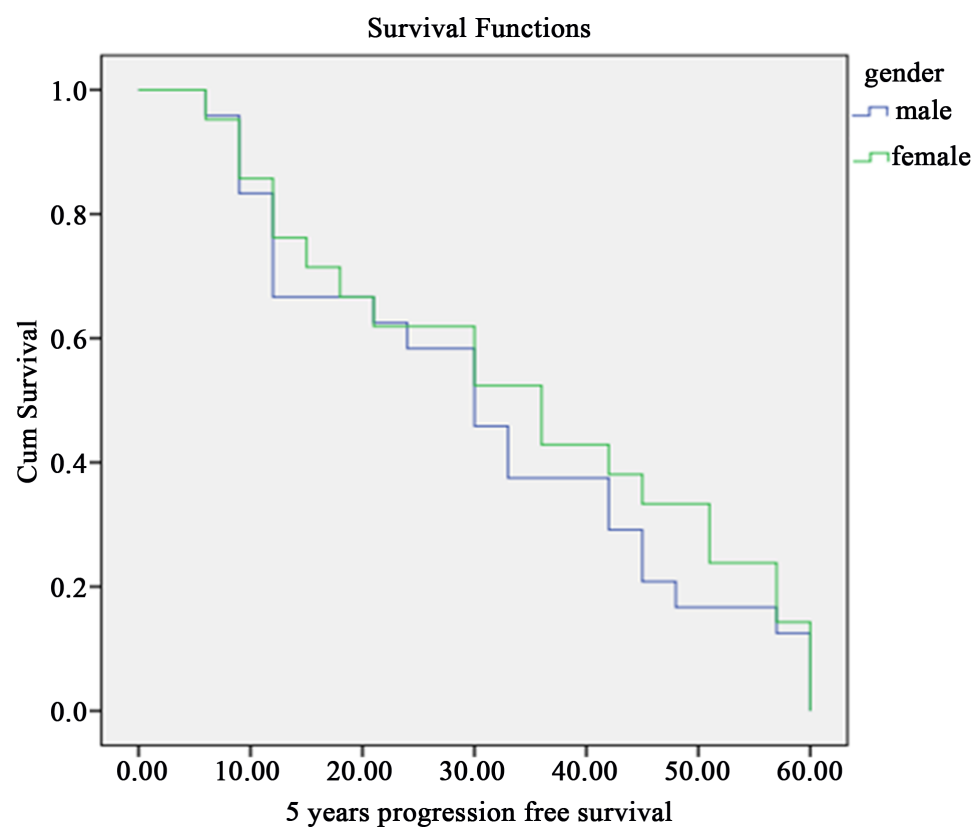

Figure 7. Progression free survival in relation to patient gender.

Table 8. Analysis of PFS in relation to covariables (COX regression model).

\begin{tabular}{ccccccc}
\hline \multicolumn{7}{c}{ Variables in the Equation } \\
\hline & B & SE & Wald & df & Sig. & Exp (B) \\
\hline stage & 0.518 & 0.553 & 0.880 & 1 & 0.348 & 0.595 \\
BCL2 & 1.329 & 0.474 & 7.858 & 1 & $\mathbf{0 . 0 0 5}$ & 3.777 \\
recurrence & 12.894 & 64.441 & 0.040 & 1 & 0.841 & $398,108.921$ \\
chemotherapy & & & 9.489 & 2 & $\mathbf{0 . 0 0 9}$ & \\
Chemotherapy (1) & 2.203 & 0.824 & 7.141 & 1 & 0.008 & 0.111 \\
Chemotherapy (2) & 2.391 & 0.777 & 9.478 & 1 & 0.002 & 0.092 \\
\hline
\end{tabular}




\section{Discussion}

Hodgkin's lymphomas habitually include lymph nodes of the neck and mediastinum, while extranodal lymphomas represent just $5 \%$ from claiming HLs for illustration in the tonsils. On contrast, roughly $30 \%$ about NHLs demonstrate heterogeneous extranodal manifestations, for example, such that in the major salivary glands, paranasal sinuses, mandible, maxilla and Waldeyer's ring [15] other than the gastrointestinal tract, the head and neck are commonly involved as an extranodal site in NHL, affecting $11 \%-33 \%$ of patients [16]. Clinically, head and neck lymphomas absent the definite characteristics that might empower attribution to a particular lymphoma type without biopsy and histological proof. In particular, with respect to lymphomas having aggressive behavior, prompt histological proof will be essential for patient management, early treatment initiation and frequently for the outcome [17].

DLBCL is an aggressive type of NHL in which the IPI is used as a prognostic score in the clinical setting to determine outcomes. Patients who have similar IPI scores have varied outcomes, molecular signatures have been studied to prognosticate patients with DLBCL. Studies have revealed that the expression of certain genes is associated with poor outcomes [12] [18]. BCL2 is an anti-apoptotic protein that also has an antiproliferative effect and is a powerful prognostic marker before rituximab. Studies showed that the addition of rituximab has eliminated the negative impact of the BCL2 expression [10] [12] [13] [19]. However, the prognostic value of BCL2 protein in DLBCL is still controversial [14] [15] [20] [21], reflecting the heterogeneity of the disease and different molecular techniques used. BCL2 overexpression has been identified with different methods, such as IHC, Western blot, chimeric genomic hybridization, fluorescence in situ hybridization, and cDNA microarray. Studies using different techniques have shown varied results [22] [23] [24] [25].

In fact, some studies suggest that patients with BCL2 gene rearrangements have better survival. In studies using Southern blot analysis, the presence of BCL2 gene rearrangement did not appear to be predictive of survival except for few studies showed worse survival [22] [23] [24] [25]. Multiple studies have looked at the expression of BCL2 using immune stains and some have found no difference in OS [22], while other studies found that BCL2 expression was prognostic in DLBCL and associated with poor outcomes [18] [26].

In this project, we studied the expression of BCL2 in DLBCLs. BCL2 in addition to being an antiapoptotic protein; has a role in resistance to chemotherapeutic agents. Eighty percent of the studied DLBCL cases demonstrated positive BCL2 expression. Akay OM et al. (2014) [27] reported the same percentage of BCL2 expression in the worked cases of DLBCL. They also found that BCL2 overexpression (more than $80 \%$ ) was associated with slow response or resistance to chemotherapy and a negative influence on OS [27]. Akay OM et al. (2014) concluded that rearrangements of BCL2 and expression of this oncogenic protein may serve as prognostic markers in DLBCL patients [27].

Positive BCL2 expression significantly associated with shortened OS and PFS, 
the incidence of recurrence and chemoresistant patient response. The incidence of patients' death also was positively correlated with positive BCL2 expression, but the statistically significant difference is not reached $(P=0.09)$. In accordance with these findings, high BCL2 expression was associated with short survival in many studies [11] [18] [27] [28]. Expression of BCL2 is a prognostic factor that is independent of IPI score and other indicators of poor clinical outcomes in patients with several types of cancer [18] [24] [27] [28] including aggressive NHL, acute myelogenous leukemia [11] and prostatic adenocarcinoma [27]. BCL2 is an independent prognostic factor on DFS [29]. Patients with DLBCL who express BCL2 proteins are high-risk groups with poor OS and they can't achieve better response to the usual regimen [30] [31]. The OS for patients with DLBCL had poor survival when BCL2 was overexpressed, poor survival seen in both $A B C$ and GCB subtypes when BCL2 positive [22] [26] [31] [32]. This is in concordance with the study by Rantanen et al. which showed that BCL2 positivity had a bearing on survival and was associated with poor outcomes, especially in those who had received anthracycline-based chemotherapy [33]. Results different from these were seen in the study by Iqbal et al. [9] [11] which showed that BCL2 overexpression was associated with poor survival in the non-GCB and not the GCB subtype. However, BCL2 overexpression was not associated with poor survival in DLBCL as a whole. These studies were in the prerituximab era [9] [11].

Contradictory to our findings, Otilia Labău, Gabriela Mutiu did not find a statistically significant relation between BCL2 expression with response to chemotherapy [6] [8]. In another study by Mounier et al. (2003), an analysis of the GELA trial demonstrated that the benefit of rituximab appeared limited to patients with lymphoma that overexpressed bCL2 on IHC [13] [19]. The outcomes of patients with DLBCL with BCL2 overexpression have been varied with various studies [16] [22] [27] [32].

In DLBCL, the inhibitory action of BCL2 on apoptosis is hypothesized as a cause of chemotherapy resistance and this notion was supported by several clinical studies in the prerituximab era demonstrating an inverse correlation between BCL2 protein expression and survival. Studies carried out in the postrituximab era, however, raise the question of whether BCL2 remains a biomarker of treatment failure and many studies have demonstrated that this is no longer the case. Patients in both CHOP and R-CHOP arms had better survival when BCL2 negative [10] [12] [26] [32].

The causes of variation in the results are due to variable techniques were used to assess BCL2 expression in various studies that is a factor that causes inconsistent survival results in these studies. Survival could be modified by several contributory factors as CD10, BCL6 MUM-1 [27] bak, bax, BCL Xs [27] [33] [34] that associated with poor outcomes in DLBCL. Here, in our study, we studied BCL2 only.

\section{Summary and Conclusion}

DLBCL is a heterogeneous disease that displays a highly variable clinical out- 
come. This study was conducted to evaluate BCL2 expression in 45 patients diagnosed with DLBCL of the head and neck region and correlate the level of its immunohistochemical expression with different clinicopathological variables. Positive BCL2 expression was significantly associated with poor OS, PFS and chemoresistant patient response $(\mathrm{P} \leq 0.05)$. No statistically significant differences in BCL2 expression regarding the patients' Ann Arbor clinical stage, age group and tumor site (nodal or extra-nodal, $(\mathrm{p}>0.05)$ using the Chi-square test. In conclusion, BCL2 expression could be considered a predictor for patients' chemotherapeutic response, OS and PFS.

\section{Fund}

Nil.

\section{Conflicts of Interest}

No conflict of interest.

\section{References}

[1] Epstein, J.B., Epstein, J.D., Le, N.D. and Gorsky, M. (2001) Characteristics of Oral and Paraoral Malignant Lymphoma: A Population-Based Review of 361 Cases. Oral Surgery, Oral Medicine, Oral Pathology, Oral Radiology, and Endodontology, 92, 519-525. https://doi.org/10.1067/moe.2001.116062

[2] Kemp, S., Gallagher, G., Kabani, S., Noonan, V. and O'Hara, C. (2008) Oral Non Hodgkin's Lymphoma: Review of the Literature and World Health Organization Classification with Reference to 40 Cases. Oral Surgery, Oral Medicine, Oral Pathology and Oral Radiology, 105, 194-201.

https://doi.org/10.1016/j.tripleo.2007.02.019

[3] Mardi, K., Sharma, M., Bhardwaj, M., Rao, M., Pradesh, H., Mardi, K., et al. (2019) p53 expression in colorectal carcinomas and its correlation with clinic. Eduki hau blokeatuta dauka zure erakundeak/Contenido bloqueado por su organización. 2017-20.

[4] Armitage, J.O. and Weisenburger, D.D. (1998) New Approach to Classifying NonHodgkin's Lymphomas: Clinical Features of the Major Histologic Subtypes. Journal of Clinical Oncology, 16, 2780-2795. https://doi.org/10.1200/JCO.1998.16.8.2780

[5] Coiffier, B. (2007) Rituximab Therapy in Malignant Lymphoma. Oncogene, 26, 3603-3613. https://doi.org/10.1038/sj.onc.1210376

[6] Sehn, L.H., Berry, B., Chhanabhai, M., Fitzgerald, C., Gill, K., Hoskins, P., Klasa, R., Savage, K.J., Shenkier, T., Sutherland, J., et al. (2007) The Revised International Prognostic Index (R-IPI) Is a Better Predictor of Outcome than the Standard IPI for Patients with Diffuse Large B Cell Lymphoma Treated with R-CHOP. Blood, 109, 1857-1861. https://doi.org/10.1182/blood-2006-08-038257

[7] Moskowitz, C. (2012) Diffuse Large B Cell Lymphoma: How Can We Cure More Patients in 2012? Best Practice \& Research Clinical Haematology, 25, 41-47. https://doi.org/10.1016/j.beha.2012.01.008

[8] Labău, O. and Mutiu, G. (2010) BCL2 Family Related Genes Expression and Chemotherapy Response in Diffuse Large B-Cell Lymphoma. Annals of the Romanian Society for Cell Biology, 15, 71-76. 
[9] Yan, L.X., Liu, Y.H., Luo, D.L., Zhang, F., Cheng, Y., Luo, X.L., et al. (2014) MYC Expression in Concert with BCL2 and BCL6 Expression Predicts Outcome in Chinese Patients with Diffuse Large B-Cell Lymphoma, Not Otherwise Specified. PLoS ONE, 9, 1-17. https://doi.org/10.1371/journal.pone.0104068

[10] Reed, J.C. (1998) BCL-2 Family Proteins. Oncogene, 17, 3225-3236. https://doi.org/10.1038/sj.onc.1202591

[11] Dave, J., Campo, E., Iqbal, J., Neppalli, V.T., Wright, G., Dave, B.J., et al. (2006) BCL2 Expression Is a Prognostic Marker for the Activated B-Cell-Like Type of Diffuse Large B-Cell Lymphoma. Journal of Clinical Oncology. https://www.researchgate.net/publication/7354933

[12] Dunleavy, K. and Wilson, W.H. (2011) Differential Role of BCL2 in Molecular Subtypes of Diffuse Large B-Cell Lymphoma. Clinical Cancer Research, 17, 7505-7507. https://doi.org/10.1158/1078-0432.CCR-11-2372

[13] Tang, S.C., Visser, L., Hepperle, B., Hanson, J. and Poppema, S. (1994) Clinical Significance of BCL-2-MBR Gene Rearrangement and Protein Expression in Diffuse Large-Cell Non-Hodgkin's Lymphoma: An Analysis of 83 Cases. Journal of Clinical Oncology, 12, 149-154. https://doi.org/10.1200/JCO.1994.12.1.149

[14] Schraders, M., De Jong, D., Kluin, P., Groenen, P. and Van Krieken, H. (2005) Lack of BCL-2 Expression in Follicular Lymphoma May Be Caused by Mutations in the BCL2 Gene or by Absence of the T(14;18) Translocation. Journal of Pathology, 205, 329-335. https://doi.org/10.1002/path.1689

[15] Swerdlow, S.H., Campo, E., Harris, N.L., et al. (2008) WHO Classification of Tumours of Haematopoietic and Lymphoid Tissues. In: Bosman, F.T., Jaffe, E.S., Lakhani, S.R. and Ohgaki, H., Eds., World Health Organization Classification of Tumours, IARC, Lyon, France.

[16] Wulfrank, D., Pauwels, C., Roels, H. and De Schryver, A. (1987) Extranodal NonHodgkin's Lymphoma of the Head and Neck. Radiotherapy and Oncology, 8, 199-207. https://doi.org/10.1016/S0167-8140(87)80243-8

[17] Sohani, A.R. and Hasserjian, R.P. (2010) Diagnosis of Burkitt Lymphoma and Related Highgrad B-Cell Neoplasms. Surgical Pathology Clinics, 3, 1035-1059. https://doi.org/10.1016/j.path.2010.09.010

[18] Lossos, I.S., Czerwinski, D.K., Alizadeh, A.A., Wechser, M.A., Tibshirani, R., Botstein, D., et al. (2004) Prediction of Survival in Diffuse Large-B-Cell Lymphoma Based on the Expression of Six Genes. The New England Journal of Medicine, 350, 1828-1837. https://doi.org/10.1056/NEJMoa032520

[19] Mounier, N., Briere, J., Gisselbrecht, C., Emile, J.-F., Lederlin, P., Sebban, C., et al. (2003) Rituximab plus CHOP (R-CHOP) Overcomes BCL-2-Associated Resistance to Chemotherapy in Elderly Patients with Diffuse Large B-Cell Lymphoma (DLBCL). https://doi.org/10.1182/blood-2002-11-3442

[20] Maartense, E., Schuuring, P.M., Kluin, M.H.H., Kramer, J., Hermans, E., Wijburg, K., et al. (2011) Large B-Cell Lymphoma Clinical Relevance of BCL2, BCL6, and MYC Rearrangements in Diffuse.

[21] Iqbal, J., Meyer, P.N., Smith, L.M., Johnson, N.A., Vose, J.M., Greiner, T.C., et al. (2011) BCL2 Predicts Survival in Germinal Center B-Cell-Like Diffuse Large B-Cell Lymphoma Treated with CHOP-Like Therapy and Rituximab. Clinical Cancer Research, 17, 7785-7795. https://doi.org/10.1158/1078-0432.CCR-11-0267

[22] Van Imhoff, G.W., Boerma, E.J.G., Van Der Holt, B., Schuuring, E., Verdonck, L.F., Kluin-Nelemans, H.C., et al. (2006) Prognostic Impact of Germinal Center-Associated Proteins and Chromosomal Breakpoints in Poor-Risk Diffuse Large B-Cell Lym- 
phoma. Journal of Clinical Oncology, 24, 4135-4142.

https://doi.org/10.1200/JCO.2006.05.5897

[23] Offit, K., lo Coco, F., Louie, D.C., Parsa, N.Z., Leung, D., Portlock, C., et al. (1994) Rearrangement of the BCL-6 Gene as a Prognostic Marker in Diffuse Large-Cell Lymphoma. The New England Journal of Medicine, 331, 74-80. https://doi.org/10.1056/NEJM199407143310202

[24] Barrans, S.L., O’Connor, S.J.M., Evans, P.A.S., Davies, F.E., Owen, R.G., Haynes, A.P., et al. (2002) Rearrangement of the BCL6 Locus at 3Q27 Is an Independent Poor Prognostic Factor in Nodal Diffuse Large B-Cell Lymphoma. British Journal of Haematology, 117, 322-332. https://doi.org/10.1046/j.1365-2141.2002.03435.x

[25] Iqbal, J., Greiner, T.C., Patel, K., Dave, B.J., Smith, L., Ji, J., et al. (2007) Distinctive Patterns of BCL6 Molecular Alterations and Their Functional Consequences in Different Subgroups of Diffuse Large B-Cell Lymphoma. Leukemia, 21, 2332-2343. https://doi.org/10.1038/sj.leu.2404856

[26] Hans, C.P., Weisenburger, D.D., Greiner, T.C., Gascoyne, R.D., Delabie, J., Ott, G., et al. (2004) Confirmation of the Molecular Classification of Diffuse Large B-Cell Lymphoma by Immunohistochemistry Using a Tissue Microarray.

https://doi.org/10.1182/blood-2003-05-1545

[27] Akay, O.M., Aras, B.D., Isiksoy, S., Toprak, C., Mutlu, F.S., Artan, S., et al. (2014) BCL2, BCL6, IGH, TP53, and MYC Protein Expression and Gene Rearrangements as Prognostic Markers in Diffuse Large B-Cell Lymphoma: A Study of 44 Turkish Patients. Cancer Genetics, 207, 87-93. https://doi.org/10.1016/j.cancergen.2014.02.001

[28] Veelken, H., Vik Dannheim, S., Schulte Moenting, J., Martens, U., Finke, J. and Schmitt-Graeff, A. (2007) Immunophenotype as Prognostic Factor for Diffuse Large B-Cell Lymphoma in Patients Undergoing Clinical Risk-Adapted Therapy. Annals of Oncology, 18, 931-939.

https://academic.oup.com/annonc/article-lookup/doi/10.1093/annonc/mdm012 https://doi.org/10.1093/annonc/mdm012

[29] Bubendorf, L., Sauter, G., Moch, H., Jordan, P., Blöchlinger, A., Gasser, T.C., et al. (1996) Prognostic Significance of BCL-2 in Clinically Localized Prostate Cancer. The American Journal of Pathology, 148, 1557-1565.

[30] Hermine, O., Haioun, C., Lepage, E., d'Agay, M., Briere, J., Lavignac, C., et al. (1996) Prognostic Significance of BCL-2 Protein Expression in Aggressive Non-Hodgkin's lymphoma. Groupe d'Etude des Lymphomes de l'Adulte (GELA). Blood, 87, 265-272. https://doi.org/10.1182/blood.V87.1.265.265

[31] Rashed, H., Abdelrahman, A.E., Ismail, E., Obaya, A. and Abdelhamid, M. (2017) Prognostic Significance of Double Expression of C-MYC and BCL2 in Diffuse Large B Cell Lymphoma. Clinical Lymphoma, Myeloma \& Leukemia, 17, S360. https://doi.org/10.1016/j.clml.2017.07.193

[32] Lakshmaiah, K., Babu, K., Dasappa, L., Abraham, L., Suresh Babu, M., Premalatha, C., et al. (2017) BCL2 and Subtype as Prognostic and Predictive Markers of Diffuse Large B-Cell Lymphoma. Clinical Cancer Investigation Journal, 6, 103. https://doi.org/10.4103/ccij.ccij_13_17

[33] Rantanen, S., Monni, O., Joensuu, H., Franssila, K. and Knuutila, S. (2001) Causes and Consequences of BCL2 over Expression in Diffuse Large B-Cell Lymphoma. Leukemia \& Lymphoma, 42, 1089-1098.

https://doi.org/10.3109/10428190109097729

[34] van den Brand, M., Garcia-Garcia, M., Mathijssen, J.J.M., Colomo, L., Groenen, 
P.J.T.A., Serrano, S., et al. (2016) Partial Lack of BCL2 in Follicular Lymphoma: An Unusual Immunohistochemical Staining Pattern Explained by Ongoing BCL2 Mutation. Pathology, Research and Practice, 212, 148-150.

https://doi.org/10.1016/j.prp.2015.12.001 